\title{
Oleander Poisoning as an Example of Self-Medication Attempt
}

\author{
Iş11 Bavunoğlu ${ }^{1}$, Musa Balta ${ }^{1}, Z^{2}$ eynepTürkmen² \\ ${ }^{1}$ Department of Internal Medicine, İstanbul University Cerrahpaşa School of Medicine, İstanbul, Turkey \\ ${ }^{2}$ Institute of Forensic Sciences, İstanbul University, Istanbul, Turkey
}

Background: There is an increasing interest in herbal products as a self-medication method in recent years. Some plant extracts either turn into drugs over time or are consumed directly without treatment. One of these plants is Nerium oleander L., which is a potentially lethal plant, since it has cardiac glycosides. However, numerous researches of its extracts have been performed against cancer cell lines in recent literature. This contradiction leads to misinterpretation and induces the prevalence of intoxication or fatal cases.

Case Report: This case is associated with an oleander-poisoned patient, who was admitted to the Emergency unit 20 hours after the first dose, and 8 hours after the second dose. Although she lives in a metropolis and has a higher level of educationand numerous hospital facilities available, she had decided to take self-medication for her Hashimoto's thyroiditis and malignant thyroid disease which was caused by her apprehensive thoughts. Oleandrin was detected in the urine at a concentration of $3.2 \mathrm{ng} / \mathrm{mL}$ and in the serum at a concentration of $8.4 \mathrm{ng} / \mathrm{mL}$ by chromatographic analysis at the time of admission.

Conclusion: This case represents the misunderstanding of herbal treatments by the community. Promoting awareness of the potential toxicity of this plant among the public may help to reduce the incidence of poisoning due to Nerium species.

Keywords: Herbal treatment, oleandrin poisoning, self-medication
The consumption of herbal products are increasing as a selfmedication method in recent years. It is reported that these products are especially used for slimming, muscle enhancing, erectile dysfunction and cancer treatment (1). However, herbal products are presented as harmless under the mask of the term "natural", while using other therapeutic drugs together with plant derivatives have increased the hazard. In addition, some products, which are offered by special mystical formulations, lead to problems by abusing the expectations of users, especially in diseases such as cancer.

Nerium oleander L. is an evergreen shrub which is native to the Mediterranean region. Some preparations of this plant have been used over the years for indigestion, malaria, leprosy, mental or venereal diseases or abortifacients. Numerous researches on this promising agent have been and are still being performed to investigate its use as a chemotherapeutic agent (2). It is reported that longer use as therapeutic agent has substantial adverse gastrointestinal side effects (3).

The mechanism of action of these cardiac glycosides is as follows: inhibition of Na-K ATPase enzyme, which results in an increasing intracellular concentration of $\mathrm{Na}^{+}$and decreasing $\mathrm{K}^{+}$. This affects the $\mathrm{Na}^{+} / \mathrm{Ca}^{++}$exchange channels resulting in an increase in intracellular $\mathrm{Ca}^{++}$ions that leads to an increased force of concentration (positive inotropic effect). However, inhibition of the $\mathrm{Na}^{+} / \mathrm{K}^{+}$ATPase pump also affects the intracellular movement of $\mathrm{K}^{+}$leading to hyperkalemia. In acute poisoning by cardiac glycosides, the degree of hyperkalemia correlates to the severity of toxicity (3).

Exposure to oleander by humans may occur by accidental, child ingestion, as a herbal supplement and/or for criminal purposes (4-6). The first signs are gastrointestinal discomfort, nausea and vomiting, increased salivation and diarrhea. These

This case was presented at the $2^{\text {nd }}$ International Congress and Workshop of Forensic Toxicology, on 26-30 May 2016 in Ankara, Turkey

Address for Correspondence: Dr. Işıl Bavunoğlu, Department of Internal Medicine, İstanbul University Cerrahpaşa School of Medicine, İstanbul, Turkey

Phone: +90542 4521517 ; +905057142545 e-mail: isilbavunoglu@gmail.com

Received: 16 March $2015 \quad$ Accepted: 3 July 2015 • DOI: 10.5152/balkanmedj.2016.150307

Available at www.balkanmedicaljournal.org 
are followed by neurological symptoms and cardiac symptoms manifested as sinus bradycardia and other arrhythmias, atrioventricular (AV) block, atrial and/or ventricular fibrillation. Tremor, drowsiness, ataxia, visual disturbances (yellow vision), mydriasis, numbness and weakness were the signs in neurological examination in $N$. oleander $\mathrm{L}$. poisoning (3).

Literature survey showed that different analytical methods for the identification and quantification of oleandrin in biological matrices have been developed recently. Some of these studies have been conducted to develop methodologies to determine the oleandrin together with other compounds in the same group. Some of them have been represented in the determination of the oleandrin directly specific to identify case history. These studies include comparative Immunoassay Techniques by Dasgupta et al. (7). High Performance Thin Layer Chromatography (HPTLC) was reported as a method used to determine oleandrin in autopsied samples (8). One of the expensive techniques, Liquid Chromatography-Tandem Mass Spectrometry (LC-MS/MS) has also been used in the investigation of the clinical- and forensic-related cases $(5,6)$.

This study was evaluated under the scope of Ethics Committee Decision 10231, made by the Cerrahpaşa Medical School, Head of Ethics Committee on April 15, 2008. The patient has accepted and signed the informed consent form. In this report, we aimed to exhibit both the clinical and toxicological presentation of oleander-poisoned patient.

\section{CASE PRESENTATION}

In our case, a 60 year-old female patient was admitted to the emergency unit with complaints such as diarrhea, vomiting and abdominal pain. She had a history of the Hashimoto's thyroiditis and hypertension; her medications included amlodipine, losartan, and levothyroxine. On physical examination, the patient had a heart rate of 64 beats per minute with sinus bradycardia, a blood pressure of $145 / 70 \mathrm{~mm} \mathrm{Hg}$, and the cardiac examination revealed no murmurs or gallop. In addition to these symptoms, the patient was monitored in relation to electrocardiography (ECG) changes and enzyme with suspected acute coronary syndrome although she had no chest pain but presence of epigastric pain might be equivalent to angina. Investigation was done for suspected infectious diarrhea. The toxicological investigation was requested on the specimens (blood and urine) for a definitive diagnosis.

The potassium level was $6.6 \mathrm{mEq} / \mathrm{L}(\mathrm{N}: 3.5-4.5 \mathrm{mEq} / \mathrm{L})$; other electrolyte values were normal, as was the complete blood count. The results of liver function tests were within normal limits. Sinus rhythm was present in the early ECG. The patient was monitored and hydrated and she was given
$100 \mathrm{cc}$ of $20 \%$ glucose solution and 10 units of insulin intravenously for hyperkalemia treatment. During follow-up, the electrocardiogram showed profound sinus bradycardia. Bradycardia was corrected by administration of two boli doses of Atropine (1 mg). Then, blood pressure was over 120/80 mm $\mathrm{Hg}$ in hourly follow-up and heart rate was 72 beats per minute. According to the first signs, the patient was asked whether she had been exposed to andromedotoxine (mad honey), any kind of food or herbal products, but she did not give any response to these questions. Since she defined numbness in her mouth, neurological work-up was done. At that point, she had to concede that she had drank boiled water containing oleander leaves.

The patient was followed closely by monitoring and supportive care. The patient had stable vital signs and was discharged after a 3-day follow-up. ECG, metabolic disturbances and hemodynamic parameters became normal.

Systematic toxicological investigations were performed on biological samples (serum and urine) in the Forensic Toxicology Laboratory, Institute of Forensic Sciences. Screening was done by HPTLC equipment including the automatic TLC Sampler 4 (ATS 4), the automatic developing chamber ADC 2, the TLC Scanner 3 with winCATS software (CAMAG; Muttenz, Switzerland), and pre-coated silica gel 60F254 HPTLC glass plates with $200 \mu \mathrm{m}$ thickness, $20 \mathrm{~cm} \times 10 \mathrm{~cm}$, cat. No: 1.05649 (Merck; Darmstadt, Germany); confirmation was conducted byLC-MS/MS (Zivak ${ }^{\circledR}$ HPLC and Zivak ${ }^{\circledR}$ Tandem Gold Triple quadrupole; İstanbul, Turkey). According to the procedure, as mentionedin paper (9), urine and serum samples were treated properly and analyzed to investigate illegal and prescribed drugs and other poisons. Urine and serum samples were concentrated 12 and 5 times following the related extraction procedure, respectively. Besides, the plant extraction procedure was performed to obtain oleandrin in sticky juice of Nerium plant in a parallel study step.

The oleandrin in all samples was confirmed by comparing $R_{f}$ and the spectra of pure oleandrin compounds within different concentrations. Linearity of the HPTLC method was found to be acceptable with a correlation coefficient of 0.997 (Figure 1). Oleandrin was detected in the urine at a concentration of $3.2 \mathrm{ng} / \mathrm{mL}$ and in serum at a concentration of $8.4 \mathrm{ng} /$ $\mathrm{mL}$. No other toxic substances were identified in the biological specimens of the patient.

\section{DISCUSSION}

In the first evaluation of the presented patient, high potassium concentration and cardiac dysrhythmia were the most remarkable signs, together with acute gastrointestinal com- 


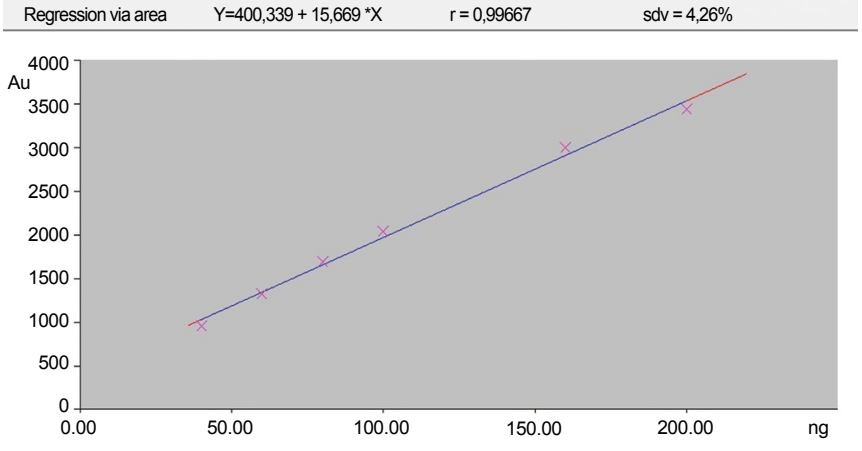

FIG. 1. Calibration curve of the oleandrin in urine sample by linear regression mode in the High Performance Thin Layer Chromatography (HPTLC) system ( $r=0.997)$

plaints (diarrhea, nausea, vomiting, abdominal pain, etc.) as similar to other non-fatal oleandrin poisoning cases $(6,10)$.

On admission, blood and urine samples of the patient were assayed for oleandrin, the major cardiac glycoside of N. oleander, which has a wide geographical range and ecological distribution throughout the world and also in Turkey and functioning as a $\mathrm{Na}^{+}-\mathrm{K}^{+}$ATPase pump inhibitor and reduces pathophysiologic changes similar to those of digoxin overdose $(3,6)$.

Systematic toxicological investigations were performed on biological samples (serum and urine) and the results revealed no poisons, therapeutics such as tricyclic antidepressants, paracetamol, benzodiazepines, carbamates, barbiturates etc., except oleandrin.

Although there are several developed methods in the literature associated with the determination of oleandrin active compounds in biological samples of the patient, it should be considered that many similar glycoside derivatives accompanied the manifestation due to the nature of herbal infusion. Here, single compound analysis by HPTLC makes a contribution to diagnosis of the case, but does not affect the management of the manifestation. In the case of poisoning resulting from herbal mixture, it should be noted that the concentration of the cardiac glycosides derivatives with similar effects in the herbal mixture is much more than the active substance, like oleandrin in our case, which is determined from the biological samples at the time of admission (6). For this reason, the immunoassay method would also be preferable for a rapid screening of cardiac glycosides to assist the clinician.

Several non-fatal or fatal cases associated with oleander have been reported to date (5-10). It can be concluded that it is difficult to determine the lethal dose for $N$. oleander poisoning, since the toxic dose will vary depending on several factors, such as the amount, plant part, and toxin concentration in the plant part ingested, and age and health of the patient at the time of ingestion (3). Also, some individual differences especially on the management of the treatment such as limited absorption from the gut, vomiting after ingestion, cardiovascular response and/or any associated disease may affect the poor correlation between dose and degree of toxicity.

The ratio between therapeutic and toxic doses of cardiac glycosides is very narrow. Side effects of these compounds occur with the accentuation of the therapeutic effects of the drug. The most important cardiac sign of digital poisoning is tachyarrhythmia. Death is usually caused by ventricular tachycardia or ventricular fibrillation (3).

Today, an irrepressible increase in cancer incidence affects the level of anxiety of individuals and drives them to take additional measures. As a reflection of this, our subject had apprehensive thoughts and chose N. oleander as aherbal treatment for malignant thyroid disease, although there was no evidence of the need for this. Even though she lives in a metropolis and has a higher level of education, as well as various hospital facilities in the area, she had decided to manage a self-medication. She dissimulated the cause of symptoms at the time of admission, but she had to concede that she had drank boiled water containing oleander leaves as a result of her worsening condition. This situation reveals that the physician must query the intake of herbal productsbesides medical drugs persistently when faced with similar findings.

There is increasing interest in herbal products as an alternative to medical treatments as a result of the influence both of the media as well as people's hunger for a natural life. A large information gap is present in recent medical practice in the context of both the placement of these plants in the treatment and their toxicities. We aimed to increase the awareness of this subject and emphasize the requirements to take the right steps in order to raise awareness of the community by specialists.

While N. oleander appeared as a promising plant for drug discovery against cancer diseases, there are nevertheless frequent encounters with intoxication cases because of its narrow therapeutic index. Unawareness and improper usage of this plant were the common features of our case presented above. Promoting the awareness to the potential toxicity of this plant among the public may help to reduce the incidence of poisoning due to Nerium species. This case represents the misunderstanding of herbal treatments by the community.

Ethics Committee Approval: This case was evaluated under the scope of Ethics Committee Decision 10231, made by the Cerrahpaşa Medical School, Head of Ethics Committee on April 15, 2008.

Informed Consent: Written informed consent was obtained from the patient.

Peer-review: Externally peer-reviewed.

Author contributions: Concept - I.B., Z.T.; Design - I.B., Z.T.; Supervision - I.B., Z.T.; Resource - Z.T.; Materials - M.B., I.B.; Data 
Collection and/or Processing - I.B., Z.T.; Analysis and/or Interpretation - Z.T.; Literature Search - I.B., Z.T.; Writing - I.B., Z.T.; Critical Reviews - I.B., Z.T.

Acknowledgements: The authors wish to thank İstanbul University Scientific Research Foundation with project number 50817.

Conflict of Interest: The authors declare that there is no conflict of interest regarding the publication of this paper.

Financial Disclosure: Authors have declared that chemical agents and consumables used in chromatographical methods were supplied from the project funded by İstanbul University, Scientific Research Foundation with project number 50817.

\section{REFERENCES}

1. Türkmen Z, Türkdoğru S, Mercan S, Açıkkol M. Forensic and legal aspect of the contents of herbal and supplementary products. Bull Leg Med 2014;19:38-48. [CrossRef]

2. Newman RA, Kondo Y, Yokoyama T, Dixon S, Cartwright C, Chan D, et al. Autophagic cell death of human pancreatic tumor cells mediated by oleandrin, a lipid-soluble cardiac glycoside. Integr Cancer Ther 2007;6:354-64. [CrossRef]

3. Bandara V, Weinstein SA, White J, Eddleston M. A review of the natural history, toxinology, diagnosis and clinical management of
Nerium oleander (common oleander) and Thevetiaperuviana (yellow oleander) poisoning. Toxicon 2010;56:273-81. [CrossRef]

4. Saravanapavananthan N, Ganeshamoorthy J. Yellow oleander poisoning-a study of 170 cases. Forensic Sci Int 1988;36:24750. [CrossRef]

5. Wasfi IA, Zorob O, Alkatheeri NA, Alawadhi AM. A fatal case of oleandrin poisoning. Forensic Sci Int 2008;179:31-6. [CrossRef]

6. Pietsch J, Oertel R, Trautmann S, Schulz K, Kopp B, DreBler J. A non-fatal oleander poisoning. Int J Leg Med 2005;119:236-40. [CrossRef]

7. Dasgupta A, Risin SA, Reyes M, Actor JK. Rapid detection of oleander poisoning by Digoxin III, a new Digoxin assay: impact on serum Digoxin measurement. Am J Clin Pathol 2008;129:548-53. [CrossRef]

8. Praveen US, Yogaraje GCV, Gowtham MD, Nayak VG, Mohan BM, Rapid detection of residues of cardenolides of Nerium oleander (linn.) by High Performance Thin Layer Chromatography (HPTLC) in autopsied samples. International Symposium for Thin Layer Chromatography HPTLC 2006, Berlin, 9-11October 2006.

9. Turkmen Z, Mercan S, Cengiz S. An HPTLC method for the determination of Oleandrin in Nerium Plant Extracts and Its Application to Forensic Toxicology. J Planar Chromatogr - Mod TLC 2013;26:279-283.

10. Vallé B, Lairez O, Gandia P, Rouge D, Franchitto N. Circuitous diagnosis in concealed self-poisoning with Nerium oleander. Clin Toxicol 2012;50:228-9. [CrossRef] 